\title{
Formation mechanism of micro-flows in aqueous poly(ethylene oxide) droplets on a substrate at different temperatures
}

\author{
Hu Yin-Chun, Zhou Qiong*, Wang Yu-Feng, Song Yun-Yang and Cui Li-Shan
}

Department of Material Science and Engineering, College of Science, China University of Petroleum (Beijing), Beijing 102249, China

(C) China University of Petroleum (Beijing) and Springer-Verlag Berlin Heidelberg 2013

\begin{abstract}
The drying of aqueous poly(ethylene oxide) (PEO) droplet on a substrate at different temperatures was studied. It was found that the contact line receded when the substrate was at a temperature above $60{ }^{\circ} \mathrm{C}$. Different nucleation behavior and surface profiles of PEO films were found in different droplets drying processes. The rheological properties of aqueous PEO solutions were studied to understand the mechanism of contact line recession and micro-flow in drying aqueous PEO droplets. It was found that at low temperature, the contact line was static because of great viscous stress; while at high temperature, it receded because of great Marangoni force and the decrease of viscous stress. It was indicated that Marangoni convection was inhibited by the outward capillary flow and viscous stress at low temperature, whereas it became dominant at high temperature. Two types of mechanism for surface profiles and nucleation of PEO film from drying droplets are proposed, providing a theoretical guide for polymer solution application in oil and gas foam flooding technology.
\end{abstract}

Key words: Poly(ethylene oxide), droplet; micro-flow, nucleation, surface profile

\section{Introduction}

The micro-flow and solute transportation in drying droplets have been extensively studied based on colloidal suspensions or polymer solutions in recent years because of their important application in the fields of high-resolution ink-jet printing, thin films and coating materials (Sirringhaus et al, 2000; Park et al, 2006; Bormashenko et al, 2007; Cawse et al, 2003). Drying droplets of colloidal suspension can form "coffee ring" stains due to the capillary flow caused by contact line pinning (Deegan et al, 1997). The later studies showed that the Marangoni effect must be taken into account to investigate the droplet drying process ( $\mathrm{Hu}$ and Larson, 2006). Marangoni convection is formed due to the difference of surface tension on the surface of drying droplets, and it plays a major role in the formation of deposition patterns, and can produce solute deposits at the center rather than the edge of the droplets (Hu and Larson, 2002; 2005a; 2005b; 2006).

Viscous force varies with the solute concentration in polymer solutions, and it cannot be ignored in drying droplets of polymer solution. So the deposition pattern formed by micro-flow in drying droplets of polymer solution is complex (Kajiya et al, 2009a; 2009b). Willmer et al (2010) studied drying aqueous PEO droplets with different initial PEO

*Corresponding author. email: cuppolymer@163.com

Received August 23, 2012 concentrations, $c_{0}$, at ambient conditions. They found that a disk-like deposit of solid PEO was left when the drying droplets $c_{0}<3 \%$, and solid conical structures formed during multistage drying of droplets when $c_{0} \geq 3 \%$. They proposed a drying and deposition process comprising four stages (fixed and drying, receding contact line, "bootstrap" growth, and late drying) to interpret their experimental data. Kim et al (2011) found that the transportation direction of polymer inside the drying droplet varied with substrate temperature, and the resulting deposit patterns were also changed from center-concentrated to edge-concentrated deposit patterns by the flow dynamics. These results clearly show that controlling substrate temperature is an effective way to manipulate the micro-flows inside drying droplets and deposition patterns after the drying process.

Foam flooding oil and gas technology is an important research area in enhanced oil recovery (EOR) in China. A foam flooding system is generally comprised of a foaming agent, foam stabilizer, gas, and water etc. The foaming agent is generally a surfactant, and the foam stabilizer is a water-soluble polymer, such as polyacrylamide or polyvinylpyrrolidone. Foam stability is one key factor affecting foam flooding. Pratt (1991) and Rudin and Wasan (1993) have proposed that the interface turbulence resulting from Marangoni convection could be used in the production of residual oil or gas, and it might be a new method to enhance oil recovery. Polymer solution is widely used 
in foam flooding for enhanced oil recovery, so the flow dynamics of polymer in a foam liquid film is the key issue for development of EOR technology (Cao et al, 2003; Shi et al, 2012). PEO is a widely used water-soluble polymer in laboratories and industrial applications, and its rheological behavior is similar to polyacrylamide (Liu and Xu, 1996). In this work, we investigated the crystallization morphology and surface profile of PEO film using droplets dried on a substrate at different temperatures to explore the micro-flow in the drying droplets. The study may provide information for application of polymer solutions in foam flooding enhanced oil recovery.

\section{Materials and methods}

PEO (purchased from Sigma-Aldrich Company, $M_{\mathrm{v}}=4 \times 10^{5} \mathrm{~g} \cdot \mathrm{mol}^{-1}, T_{\mathrm{m}}=67{ }^{\circ} \mathrm{C}$ ) was dissolved in distilled water with a concentration of $5 \mathrm{wt} \%$. Glass substrates were carefully cleaned with ethanol and then water. Droplets of PEO solution (about $1 \mu \mathrm{L}$ ) were gently placed on a glass substrate with a micropipette and dried on the substrate at either $30,50,70$ or $80^{\circ} \mathrm{C}$. Then the resultant PEO film was heated to $100{ }^{\circ} \mathrm{C}$ at a heating rate of $20{ }^{\circ} \mathrm{C} / \mathrm{min}$ and kept at $100{ }^{\circ} \mathrm{C}$ for $1 \mathrm{~min}$, and then cooled to $52.5^{\circ} \mathrm{C}$ at a cooling rate of $20^{\circ} \mathrm{C} / \mathrm{min}$ for isothermal crystallization and finally it was cooled to ambient temperature.

The drying and crystallization processes were observed on a polarizing optical microscope (DM2500P, Leica Company, Germany) equipped with a THMS-600 hot stage (Linkam Scientific Instruments Ltd, England). The three-dimensional surface profile and height distribution along the diameter of the PEO film was measured using a 3D non-contact profiler (3DNCP, Nanovea Company, USA). The rheological properties of PEO solution were obtained with an interfacial rheometer (MCR301, Anton Paar, Austria) and a surface/ interfacial tensiometer (DCAT21, HAAKE, Germany). An infrared camera (SC655, FLIR Systems, USA) was used to measure the interface temperature evolution of drying droplets.

\section{Results and discussion}

\subsection{Drying process of aqueous PEO droplets on a substrate at different temperatures}

Fig. 1 shows the time-dependent images of the drying process of aqueous PEO droplets at different substrate temperatures. For a substrate at $30^{\circ} \mathrm{C}$, after the droplet was placed on the glass substrate, the contact line remained static, and then crystalline spherulites appeared from the edge to the center of the droplet. When the substrate was at temperatures of 50,70 and $80^{\circ} \mathrm{C}$, respectively, the drying process contained two different stages. First, the contact line was static; then the free liquid surface of the droplet shrunk toward the center of the droplet. The contact line receded and kept a smooth PEO film. Obviously, at a higher substrate temperature more solvent was evaporated at the second drying stage. Similar phenomena were also observed in the drying process of other aqueous polymer droplets by Kajiya et al (2009a).

\subsection{Surface profile and crystallization behavior of the deposited PEO film}

The surface profile of a deposited film is dependent on the micro-flow inside the drying droplet. Fig. 2 shows the surface profiles and height distributions of PEO films deposited at different substrate temperatures. The surface profiles of PEO films were disk-like with a radius equal to the initial droplet base radius $\mathrm{R}$ when the droplets were dried on substrates at $30{ }^{\circ} \mathrm{C}$ and $50{ }^{\circ} \mathrm{C}$, as shown in Fig. $2 \mathrm{a}$ and $2 \mathrm{~b}$. They were similar to the typical "coffee ring" phenomenon.

At a substrate temperature of $50{ }^{\circ} \mathrm{C}$, much solute was carried to the edge of droplet, indicating that the outward capillary flow was strong. However, there was more solute deposited inside the ring when droplet was dried at $70{ }^{\circ} \mathrm{C}$ and $80^{\circ} \mathrm{C}$, as shown in Fig. $2 \mathrm{c}$ and $2 \mathrm{~d}$. Particularly, at $80^{\circ} \mathrm{C}$, the peak moved to the middle of the PEO film. This should be the melting result of $\mathrm{PEO}$ at the contact line, because the melting range of PEO is between $63{ }^{\circ} \mathrm{C}$ and $75^{\circ} \mathrm{C}$. The capillary flow caused the accumulation of solute at the contact line, while Marangoni flow induced the solute deposition at the center of droplet according to the results of micro-flows studies (Deegan et al, 1997; Hu and Larson, 2006). So it can be concluded that capillary flow dominates the drying process at $30^{\circ} \mathrm{C}$ and $50{ }^{\circ} \mathrm{C}$ and the first drying stage of $70{ }^{\circ} \mathrm{C}$ and $80{ }^{\circ} \mathrm{C}$; while Marangoni convection was dominant in the second drying stage at $70^{\circ} \mathrm{C}$ and $80{ }^{\circ} \mathrm{C}$.

PEO is a linear semicrystalline polymer. Because of its intrinsic soft matter nature, the long and flexible PEO chains are easily oriented and rearranged by shear fields in the molten and solution states. The subsequent crystallization behaviour would be significantly affected due to the memory effect of resulting structures (Zhang et al, 2012; Kim et al, 2007). Fig. 3 shows the isothermal crystallization process of different PEO films. For PEO film obtained at $30{ }^{\circ} \mathrm{C}$, only scattered small spherulites appeared and arranged irregularly. However, in the case of PEO film from droplet dried on a substrate at $50{ }^{\circ} \mathrm{C}$, a large number of small spherulites appeared, and gathered together at the center of PEO film. When the PEO film obtained at even higher temperature, 70 ${ }^{\circ} \mathrm{C}$ and $80^{\circ} \mathrm{C}$, a regular ringlike nucleation phenomenon was observed. It's reasonable to deduce that the regular ringlike nucleation was induced by the micro-flows during the drying process of droplets.

\subsection{Formation mechanisms of nucleating patterns and surface profiles of PEO films from aqueous PEO droplets dried on a substrate at various temperatures}

The surface tension $(\gamma)$ and viscosity $(\eta)$ of aqueous PEO solution were measured to understand the mechanism of contact line recession at the second drying stage when the substrate temperature was at $50{ }^{\circ} \mathrm{C}, 70{ }^{\circ} \mathrm{C}$ and $80{ }^{\circ} \mathrm{C}$, respectively. Fig. $4 \mathrm{a}$ and $4 \mathrm{~b}$ shows the effects of $\mathrm{PEO}$ initial concentration on surface tension $(\gamma)$ and viscosity $(\eta)$, respectively. The value of surface tension $(\gamma)$ decreased by $8 \mathrm{mN} / \mathrm{m}$ and viscosity $(\eta)$ increased by three orders of magnitude as the PEO concentration increased from 0.5 wt $\%$ to $5 \mathrm{wt} \%$. For an aqueous PEO droplet with a solute 
$30{ }^{\circ} \mathrm{C}$
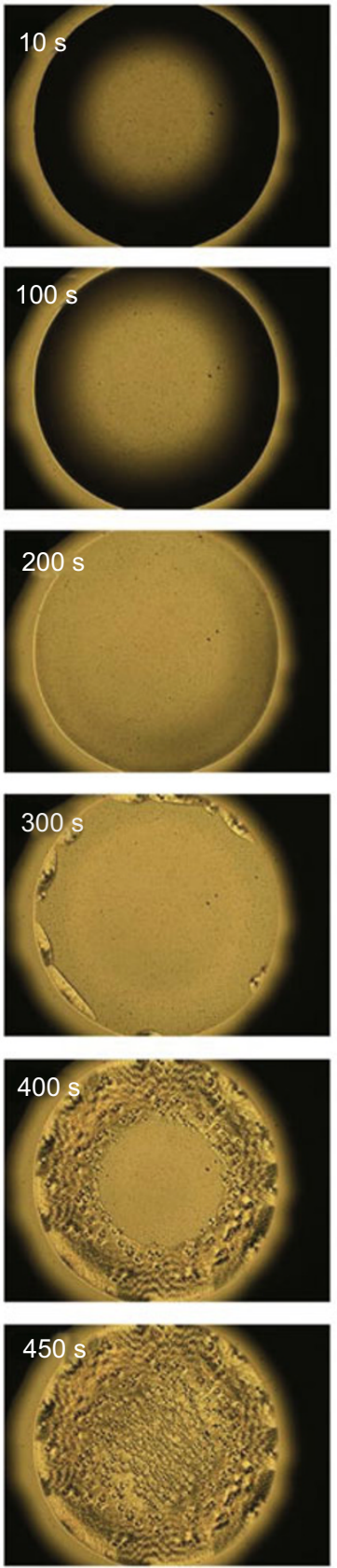

$50{ }^{\circ} \mathrm{C}$
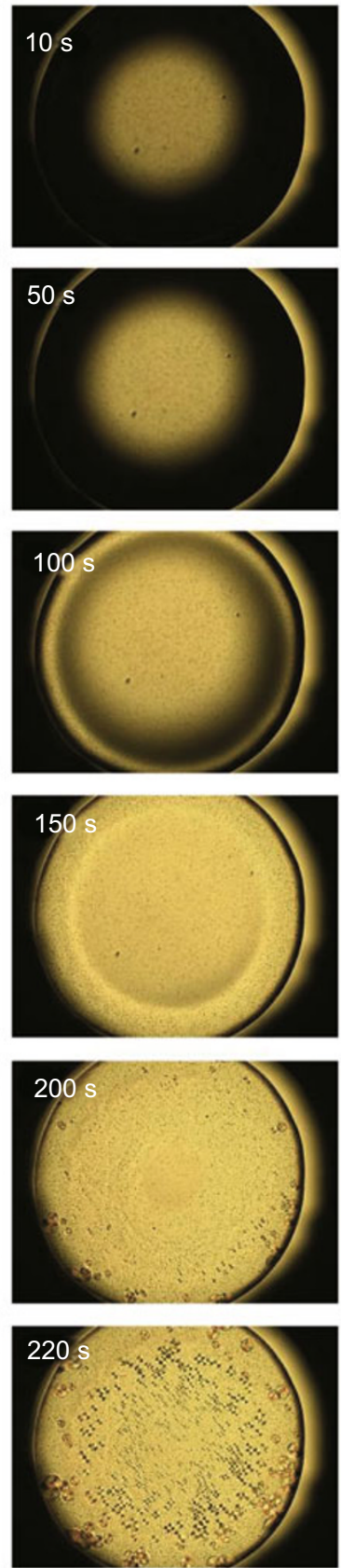

$70{ }^{\circ} \mathrm{C}$
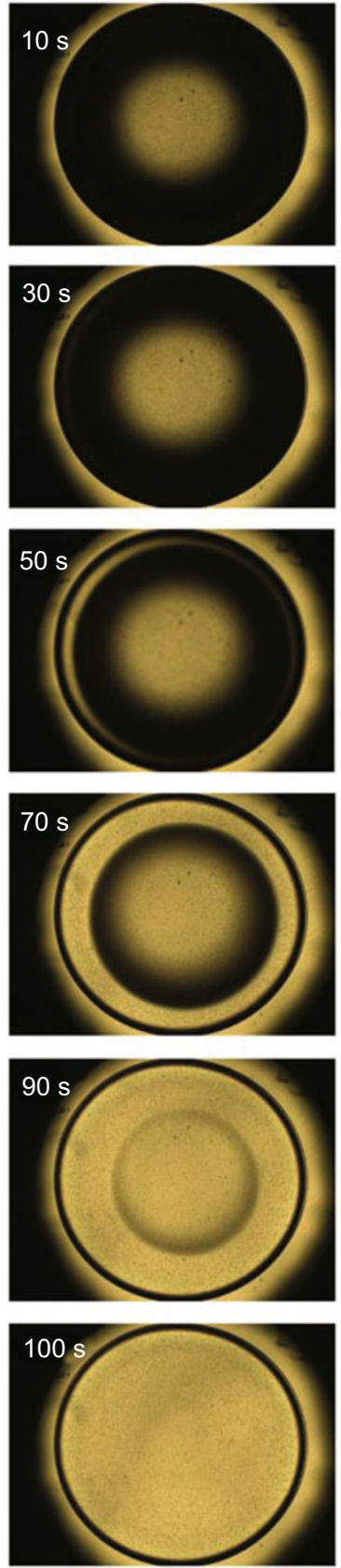

$80^{\circ} \mathrm{C}$
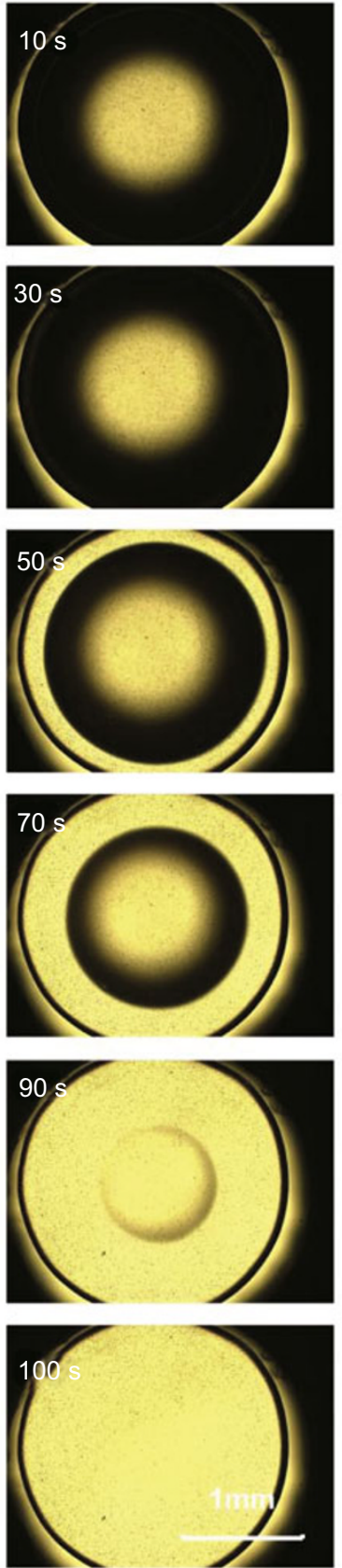

Fig. 1 Drying processes of aqueous PEO droplets on a substrate at different temperatures

concentration of $10 \mathrm{wt} \%$, the viscosity $(\eta)$ was $10.5 \mathrm{~Pa} \cdot \mathrm{s}$ at $20{ }^{\circ} \mathrm{C}$, and decreased to $4.5 \mathrm{~Pa} \cdot \mathrm{s}$ at $70{ }^{\circ} \mathrm{C}$. So the surface tension $(\gamma)$ decreased and viscosity $(\eta)$ increased sharply with increasing PEO concentration, and the rise in temperature induced a drastic decrease of viscosity $(\eta)$.

The PEO concentration became higher near the contact line because of the evaporation of water and the fixed contact line, leading to smaller surface tension $(\gamma)$ and higher viscosity $(\eta)$ in the outer region than the inner region of the droplets. When the temperature increased (the melting range of PEO is $63-67{ }^{\circ} \mathrm{C}$ ), the viscous stress decreased sharply due to the decrease of viscosity $(\eta)$. So it was demonstrated that the contact line was pinned at low temperature because of great viscous stress, and it receded at high temperature, because of the greater Marangoni force, induced by the increase of surface tension $(\gamma)$ gradient, and the sharp decrease of viscous stress.

To quantify the effect of the solute concentration gradient on the Marangoni effect, the Marangoni number $M_{\mathrm{a}}$ (Kajiya et al, 2009a) was determined as follows:

$$
M_{\mathrm{a}}=\frac{\Delta \gamma_{\mathrm{c}} L}{\eta D_{\mathrm{PEO}}}
$$

where, $\Delta \gamma_{\mathrm{c}}$ is surface tension $(\gamma)$ gradient, and $L$ is the size of the droplet where surface tension gradient $\left(\Delta \gamma_{c}\right)$ exists. $D_{\text {PEO }}$ is the diffusion constant of PEO in water. For a polymer solution, it is given by the generalized Stokes-Einstein 
(a)

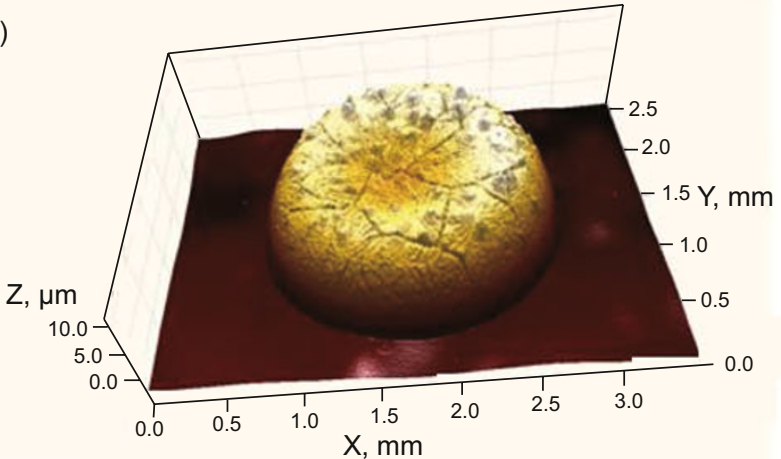

(b)

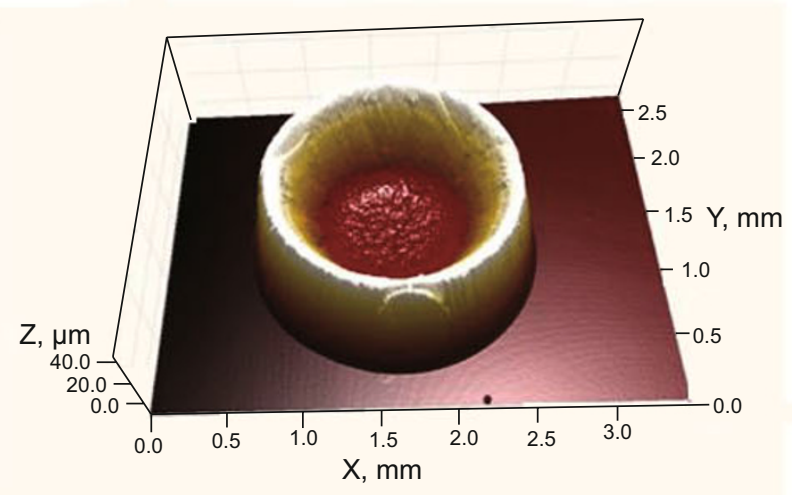

(c)

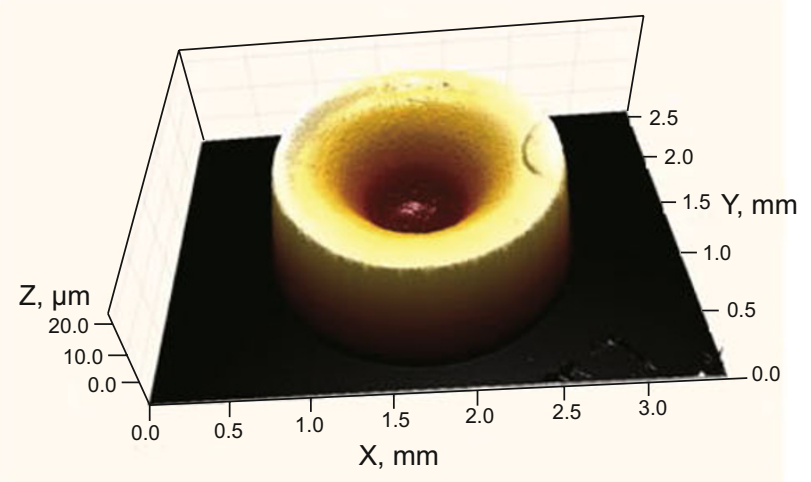

(d)

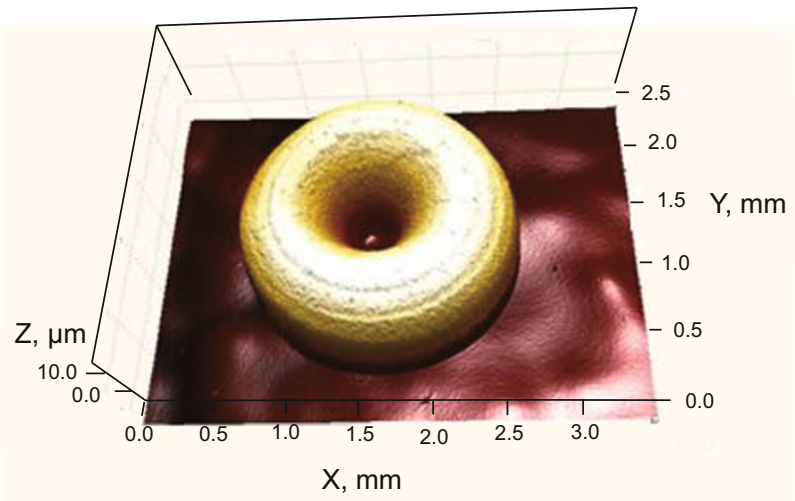

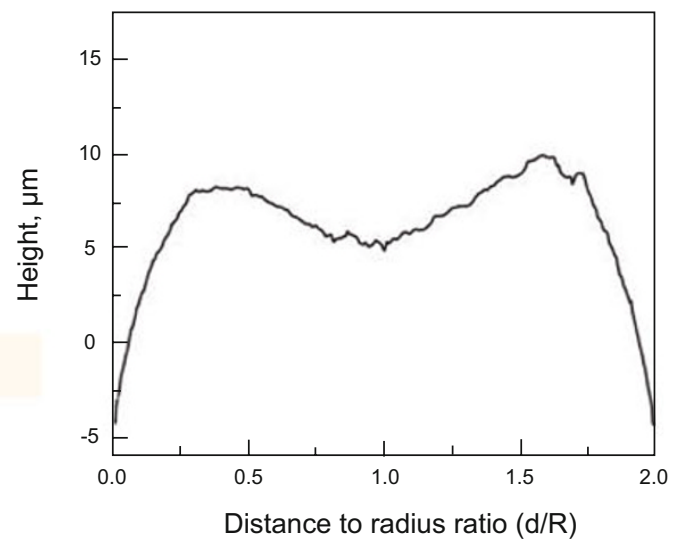
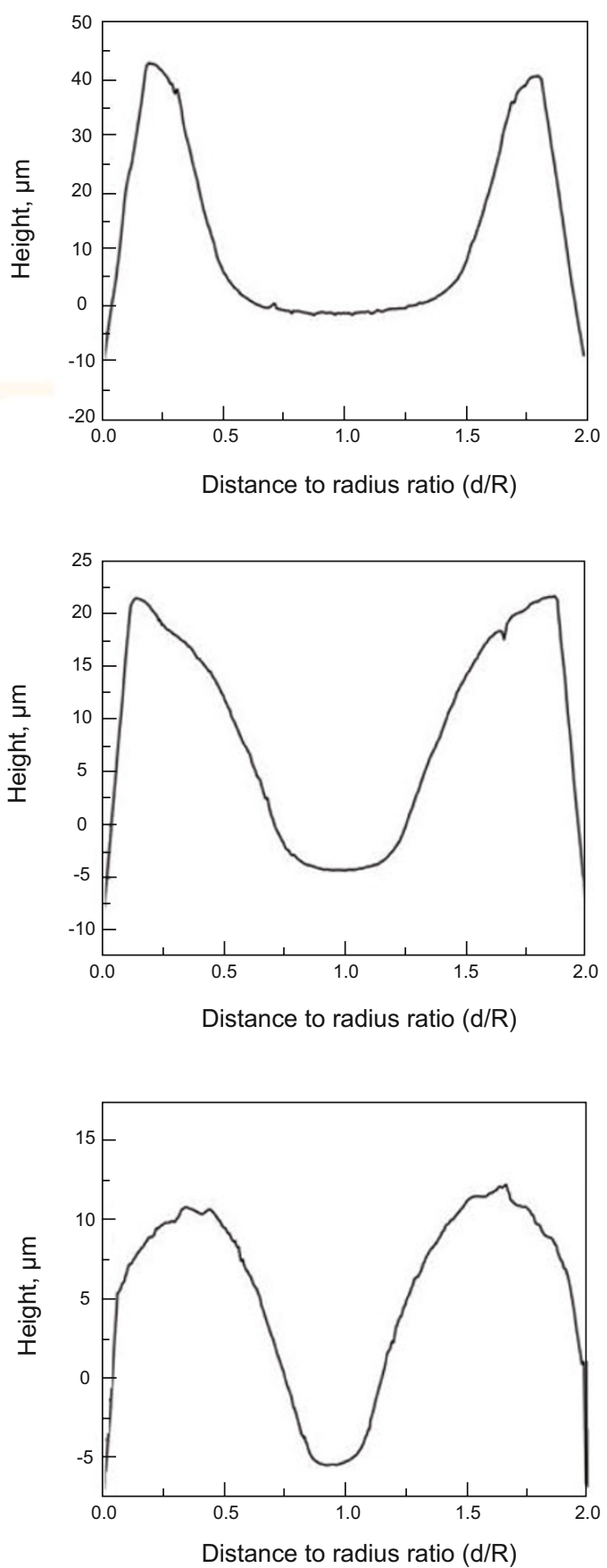

Fig. 2 Surface profiles and height distributions of PEO films deposited on a substrate at different temperatures. (a) $30{ }^{\circ} \mathrm{C}$, (b) $50{ }^{\circ} \mathrm{C}$, (c) $70{ }^{\circ} \mathrm{C}$, and (d) $80{ }^{\circ} \mathrm{C}$ 
$30{ }^{\circ} \mathrm{C}$
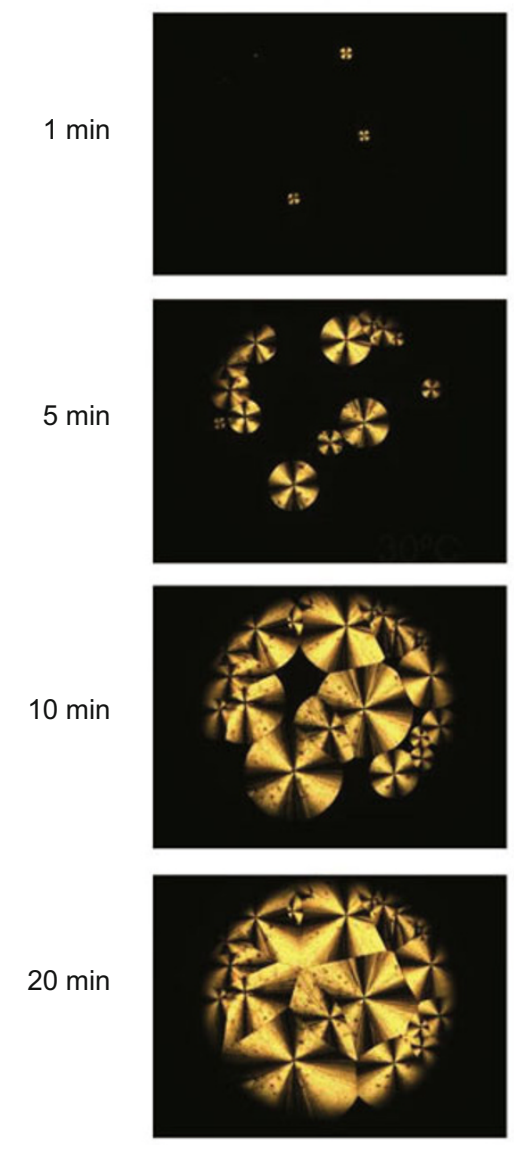

$50^{\circ} \mathrm{C}$
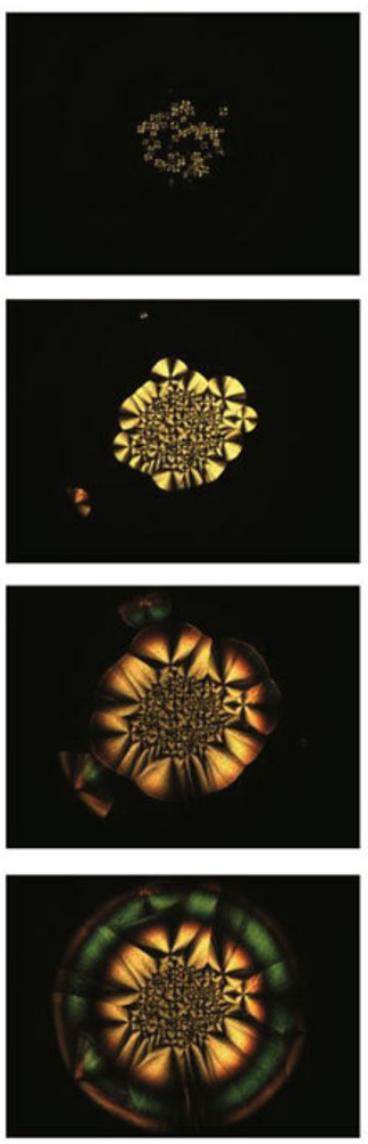

$70{ }^{\circ} \mathrm{C}$
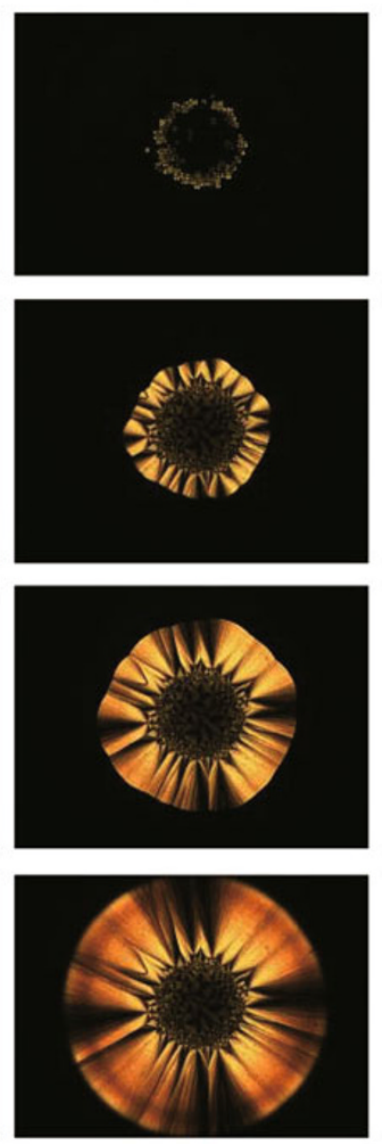

$80^{\circ} \mathrm{C}$
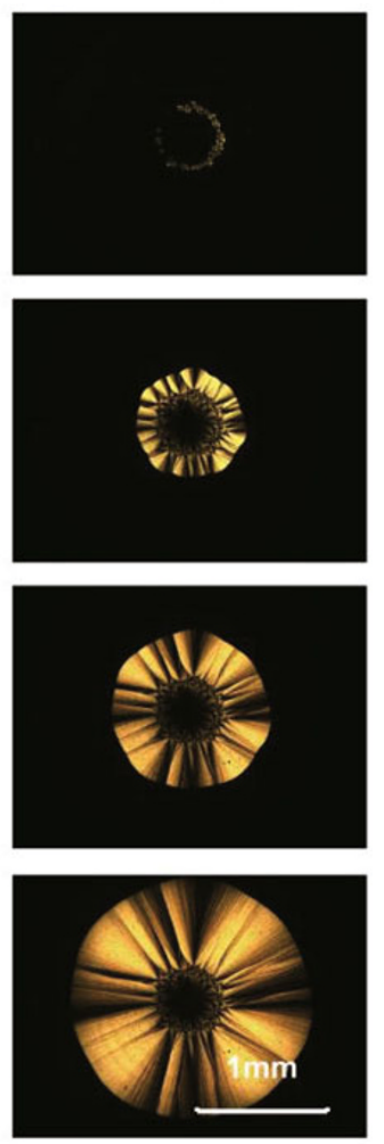

Fig. 3 Isothermal crystallization processes of PEO films obtained on a substrate at different temperatures

equation (He et al, 1990).

$$
D_{\mathrm{PEO}}=\frac{k T}{6 \pi \eta R_{0}}
$$

where Boltzmann's constant $k$ is $1.3807 \times 10^{-23} \mathrm{~J} \cdot \mathrm{K}^{-1} \cdot R_{0}$ is the size of polymer particles in solution and it is nanoscale. Therefore, Eq. (1) can be converted to

$$
M_{\mathrm{a}}=\frac{6 \pi R_{0} L}{k} \frac{\Delta \gamma_{\mathrm{c}}}{T}
$$

The solute concentration at the center of droplet remained almost the same, and the solute concentration became higher at the edge of droplet because of the evaporation of solvent and the transport of solute in the drying process (Kajiya et al, 2009a). So it is reasonable to assume the PEO concentration in the center region of droplet as $3 \mathrm{wt} \%$ and the concentration near the contact line as about $10 \mathrm{wt} \%$. The surface tension gradient $\left(\Delta \gamma_{\mathrm{c}}\right)$ can be estimated as ca. $4 \mathrm{mN} / \mathrm{m}$ (obtained from the extrapolation of Fig. 4). The $M_{\mathrm{a}}$ induced by the solute concentration gradient was of the order of $10^{6}$ at $30{ }^{\circ} \mathrm{C}$. When the substrate was at $50{ }^{\circ} \mathrm{C}, 70{ }^{\circ} \mathrm{C}$ and $80{ }^{\circ} \mathrm{C}$, the $M_{\mathrm{a}}$ was all of the order of $10^{7}$, indicating that Marangoni effect was significant and always present at the whole temperature range.

From the study of the drying process of aqueous PEO droplet, it was found that when substrate was below 50 ${ }^{\circ} \mathrm{C}$, the viscous stress was very large and the contact line remained fixed, and Marangoni effect was inhibited by the outward capillary flow and viscous stress. When the substrate was at $70{ }^{\circ} \mathrm{C}$ and $80{ }^{\circ} \mathrm{C}$, the viscous stress decreased sharply and the contact line receded, so the capillary flow disappeared and Marangoni convection became the dominant flow. Kajiya et al (2009a) also found that the competition between the Marangoni force and the viscous stress resulted in the recession of contact-line in drying aqueous poly $(\mathrm{N}$, N-dimethylacrylamide) droplets.

Based on the above study, a formation mechanism model was suggested for understanding the nucleation phenomenon and surface profile of the deposited PEO film, as shown in Fig. 5. When the drying was performed below $50{ }^{\circ} \mathrm{C}$, capillary flow dominated the drying process and solute was carried to the edge of the droplet, resulting in a disk-like PEO film. When the substrate temperature was at $60{ }^{\circ} \mathrm{C}$ or higher, the free liquid surface of droplet shrank, and Marangoni convection became the dominant flow, so much solute was carried to the middle of droplet. Marangoni convective cells formed inside the drying droplet and induced the formation of ring-like nucleation. The mechanism of the ring-like nucleation needs further research. 
(a)

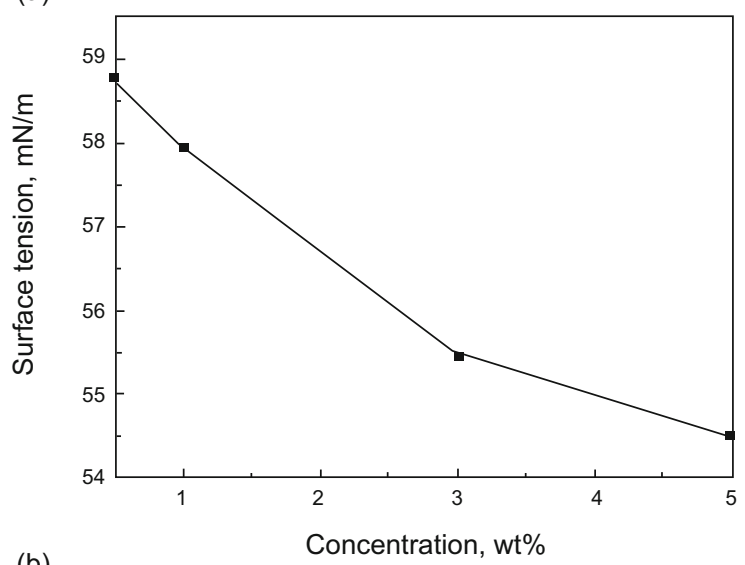

(b)

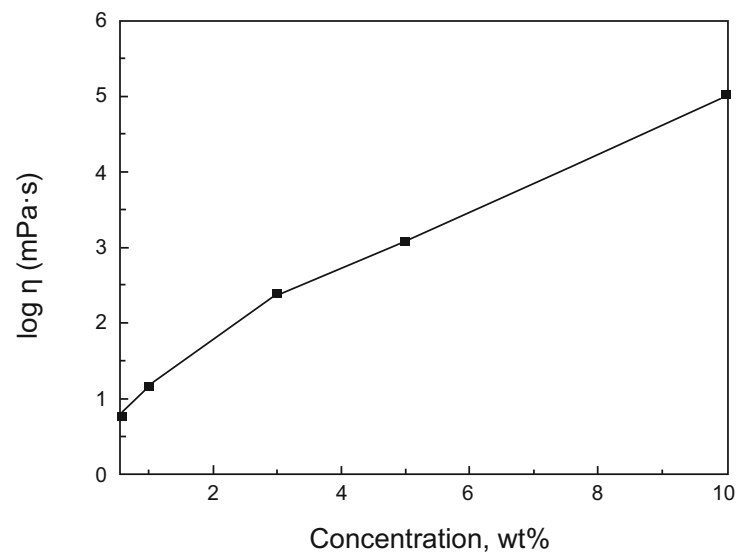

(c)

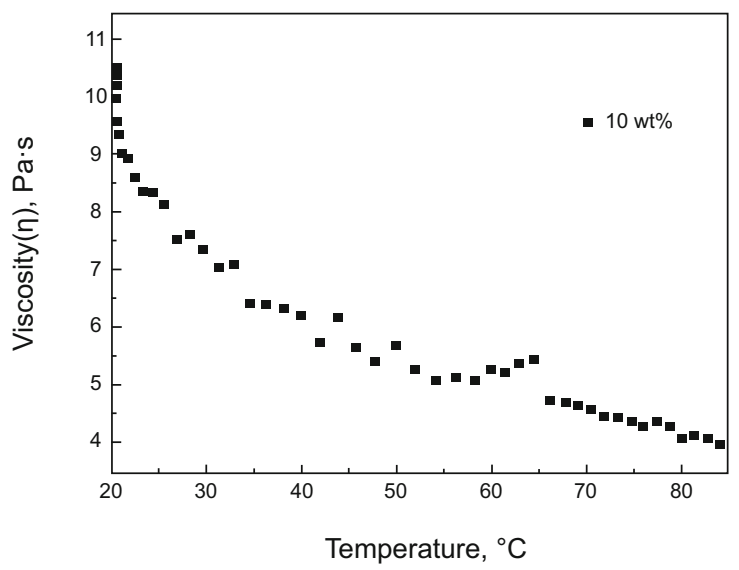

Fig. 4 The effect of PEO initial concentration on surface tension $(\gamma)(\mathrm{a})$ and viscosity $(\eta)(b)$ of aqueous PEO solution, and the effect of temperature

$(T)$ on viscosity $(\eta)$ of $10 \mathrm{wt} \%$ aqueous PEO solution (c)

\section{Conclusions}

Different nucleation phenomenon and surface profiles of PEO film were induced by the micro-flows inside aqueous PEO droplets during the drying process. The outward capillary flow was the dominant micro-flow and solute was carried to the edge of droplet at $50{ }^{\circ} \mathrm{C}$ or below, and a disklike solid "puddle" morphology formed. Marangoni flow appeared and solute was transported to the middle of droplet

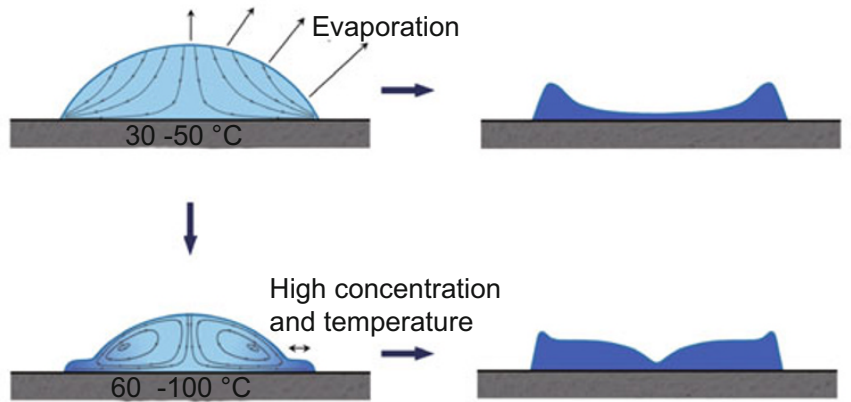

Fig. 5 Schematic diagrams of two typical surface profiles induced by micro-flows in drying aqueous PEO droplets on heated substrates

at $60{ }^{\circ} \mathrm{C}$ or higher temperatures. The surface profile of PEO film varied with the strength and duration time of micro-flows inside drying droplet. These results revealed that temperature can be used effectively to control micro-flows in drying droplets of polymer solution. The effective components of foaming agents are surfactant and polymer which could be easily transported to the edge of bubbles by capillary flow, while Marangoni flow could transport the surfactant and polymer from high density region to low density regions of foam films. According to our experimental results, we should adjust the polymer parameters according to the environment temperature to avoid the occurrence of capillary flow in the liquid film, and increase the Marangoni effect.

\section{References}

Bormashenko E, Bormashenko Y, Pogreb R, et al. Droplet behavior on flat and textured surfaces: Co-occurrence of Deegan outward flow with Marangoni solute instability. J. Colloid Interface Sci. 2007. 306: $128-132$

Cao Y, Zhang X, Li H L, et al. Application and prospect of polymer materials for oil production engineering. Oilfield Chemistry. 2003. 20(1): 94-99 (in Chinese)

Cawse J N, 1son O D, Chisholm B J, et al. Combinatorial chemistry methods for coating development V: generating a combinatorial array of uniform coatings samples. Prog. Org. Coat. 2003. 47: 128135

Deegan R D, Bakajin O, Dupont T F, et al. Capillary flow as the cause of ring stains from dried liquid drops. Nature. 1997. 389: 827-829

He M J, Chen W X and Dong X X. Polymer Physics. Fudan University Press. 1990. 114-148 (in Chinese)

$\mathrm{Hu} \mathrm{H}$ and Larson R G. Analysis of the effects of Marangoni stresses on the microflow in an evaporating sessile droplet. Langmuir. 2005a. 21: 3972-3980

$\mathrm{Hu} \mathrm{H}$ and Larson R G. Analysis of the microfluid flow in an evaporating sessile droplet. Langmuir. 2005b. 21: 3963-3971

$\mathrm{Hu} \mathrm{H}$ and Larson R G. Evaporation of a sessile droplet on a substrate. J. Phys. Chem. B. 2002.106: 1334-1344

$\mathrm{Hu} \mathrm{H}$ and Larson R G. Marangoni effect reverses Coffee-Ring depositions. J. Phys. Chem. B. 2006.110: 7090-7094

Kajiya T, Monteux C, Narita T, et al. Contact-line recession leaving a macroscopic polymer film in the drying droplets of Water-Poly(N,Ndimethylacrylamide) (PDMA) Solution. Langmuir. 2009a. 12: 69346939

Kajiya T, Monteux C, Narita T, et al. Dynamical visualization of "Coffee Stain Phenomenon" in droplets of polymer solution via fluorescent microscopy. Langmuir. 2009b. 25: 6934-6939 
Kim J-H, Ahn S I, Kim J H and Zin W-C. Evaporation of water droplets on polymer surfaces. Langmuir. 2007. 23: 6163-6169

Kim J-H, Park S-B, Kim J H, et al. Polymer transports inside evaporating water droplets at various substrate temperatures. J. Phys. Chem. C. 2011. 115: 15375-15383

Liu Z Y and Xu Y Z. Studies on rheological properties of HPAM solutions through porous media. Oilfield Chemistry. 1996. 13: 145148

Park J, Moon J, Shin H, et al. Direct-write fabrication of colloidal photonic crystal microarrays by ink-jet printing. J. Colloid Interface Sci. 2006. 298: 713-719

Pratt H R C. Marangoni flooding with water drives: A novel method for EOR? SPE Asia-Pacific Conference. Kuala Lumpur: Society of Petroleum Engineers. 1991: 337-340

Rudin J and Wasan D T. Interfacial turbulence and spontaneous emulsification in alkali-acidic oil systems. Chemical Engineering Science. 1993. 48: 2225- 2238

Shi L, Chen L, Ye Z B, et al. Effect of polymer solution structure on displacement efficiency. Petroleum Science. 2012. 9: 230-235

Sirringhaus H, Kawase T, Friend R H, et al. High-resolution inkjet printing of all-polymer transistor circuits. Science. 2000. 290: 21232126

Willmer D, Baldwin K A, Kwartnik C, et al. Growth of solid conical structures during multistage drying of sessile poly(ethylene oxide) droplets. Phys. Chem. Chem. Phys. 2010. 16: 3998-4004

Zhang Y S, Zhong L W, Yang S, et al. Memory effect on solution crystallization of high molecular weight Poly(ethylene oxide). Polymer. 2012. 53: 3621-3628

(Edited by Zhu Xiuqin) 